\title{
Development of Alkali-activated Foamed Lightweight Mortar Tungsten Mining Waste Mud-based Incorporating Expanded Cork
}

\section{Ilmed Beghoura and Joao Castro-Gomes}

C-MADE, centre of Materials and Building Technologies, Department of Civil Engineering and Architecture, University of Beira Interior, Calçada Fonte de Lameiro Edifício II das Engenharias, 6201-001 Covilhã, Portugal

\section{Abstract}

In this study, an Alkali-activation of tungsten mining waste mud (TMWM) was combined with aluminium powder (Al) as a blowing agent (gas foaming method). The synthesis of inorganic alkali-activated foamed mortar (AA-FM) and alkali-activated lightweight foamed mortar (AALW-FM) was achieved by incorporating expanded granulated cork (EGC) and one type of river sand $<2 \mathrm{~mm}$. Al powder was added first to the dry mix with the mass used varying from $0.1 \mathrm{~g}$ to $0.5 \mathrm{~g}$. Precursors and activators were included to produce a homogeneous mixture, which was placed into a mould $\left(100 \times 100 \times 60 \mathrm{~mm}^{3}\right)$,

Corresponding Author: Imed Beghoura beghoura.imed@ubi.pt

Received: 20 March 2020 Accepted: 30 April 2020 Published: 13 April 2020

Publishing services provided by Knowledge E

(c) Imed Beghoura and Joao Castro-Gomes. This article is distributed under the terms of the Creative Commons

Attribution License, which permits unrestricted use and redistribution provided that the original author and source are credited.

Selection and Peer-review under the responsibility of the RICON19 - REMINE International Conference Conference Committee.

\section{G OPEN ACCESS} and cured in the oven at $60^{\circ} \mathrm{C}$ for 24 hours. The influence of two main parameters (Al powder contents and cork particles) on the AA-FM and AALW-FM properties (compressive strength, density, expansion volume and pore size distribution) were investigated. The compressive strength of the foams in the case of highly porous structures of the AALW-FM and AA-FM achieved 4.1MPa and 13.2MPa respectively, for samples with a larger amount of Al powder $(0.5 \mathrm{~g})$. Open celled hardened of the AALW-FM and AA-FM with $0.5 \mathrm{~g}$ Al shows a high porosity of $40 \%$ and $81 \%$ respectively. Therefore, tungsten mining waste-based alkali-activated foams shows potential as a thermal insulation material in certain situations.

Keywords: Tungsten mining waste, Alkali-activated, Foamed Materials

\section{Introduction}

Research in the field of alkali-activated materials has led to the development of several new or to the improvement of some types of alkali-activated foams [1] which have been obtained from different raw and waste materials, were reported in the literature [2] and they have been proposed as a new idea which involves the production of the lightweight materials, thus combining the performance and the benefits of energy saving (carbon footprint) with the reductions of the cradle-to-gate emission obtained [3, 4]. In order to reduce the density of the foamed alkali-activated materials $[5,6]$ holes or lightweight aggregates [7] can be added for such purpose. 
Alkali-activated foams can be made using different methods. The two main methods are pre-foaming and the mixed-foaming [8]. Several foaming agents, as well as detergents, resin soap, glue resins, saponin, and hydrolysed proteins, such as keratin and similar materials [9] have been produced for this purpose. Among the methods used to produce alkali-activated foamed lightweight materials is the thermal expansion of ( $\mathrm{Na}, \mathrm{K}$ )-poly (silicate-multisiloxo) with ration Si:Al>>6 [10]. Various chemical foaming agents can be used in the foaming process of inorganic polymers [11]. Aluminium powder (Al) has been used to produce foams of inorganic polymers [11] as a chemical foaming agent beside many others such as hydrogen peroxide $\left(\mathrm{H}_{2} \mathrm{O}_{2}\right)$ and sodium perborate [12].

At present, cork is used in a wide range of application in the building as a solution of lightweight, thermal insulation and shows good environmental advantages [13, 14]. The search for alkali-activated foams offering high thermal insulation has increasingly become a target of the modern construction and building industry, as energy-efficiency of buildings in service has become of ever increasing concern [15-17]. [18] studied the impact of cork used as an alternative to sand or an alternative to stone or the plastic, mechanical, transport, microstructural and thermal properties of mortar and concrete. [19] studied the influence of cork granules for manufacture compatibility with cement and the hydration test results showed that cork granules (both natural and expanded) are compatible with cement and can be added up to $30 \%$ by weight of cement.

In the recent focus on global warming, insulating materials play an important role on the reduction of energy consumption, and the concern on the thermal performance and fire resistance of building materials has become one of the research interests [20]. Researchers have focused the attention on the reuse of waste materials by integrating them into the manufacture of new materials, thus protecting the environment and developing sustainable thermal insulation solutions $[21,22]$.

The main objective of this paper is to investigate the fundamental properties of the alkali-activated lightweight foamed mortar using a combination of $50 \%$ tungsten mining waste mud (TMWM) paste and $50 \%$ river sand $<2 \mathrm{~mm}$ using the chemical foaming method with aluminium powder (Al) as a foaming agent, and incorporating expanded granulated cork (EGC), including compressive strength, dry density and porosity. Understanding of these properties is useful to the widespread uptake of this new material.

\section{Materials and Methods}




\subsection{Materials}

In the present study, the alkali-activated foamed mortar and lightweight foamed mortar were prepared using a blend of $50 \%$ alkali-activated tungsten mining waste mud (TMWM) paste and 50\% river sand. The TMWM paste was a combination of tungsten mining waste mud (TMWM), milled waste glass (WG), and metakaolin (MK) as original materials. The precursors' particle sizes of the alkali-activated paste were sieved under $150 \mu \mathrm{m}$, and the sand with the maximum particle sizes of $2 \mathrm{~mm}$ diameter.

The TMWM was collected from the deposit field (The Panasqueira tungsten mining waste mud in Covilhã, Castelo Branco District, Portugal), and drying in the laboratory.

The milled waste glass (WG) was obtained from glass bottles by crushing and finer milling them. The waste glass was also sieved through $150 \mu \mathrm{m}$ and used as another source of silicate in the alkali-activated paste matrix.

The fine aggregate used was obtained by screening natural materials from river dredging marketed by Tabal-Sepor Areias e Argamassas, Ida. The river sand was also sieved under $2 \mathrm{~mm}$ diameter to obtain finer particles in the mortar

In this study, the particle sizes analysis of the TMWM and WG were determined as a result of the sedimentation method, British standard BS 1796, Method for test sieving while the river sand was determined with the particle size analysis - sieving method NP EN 933-1. Figure 1 show the particle sizes analysis.

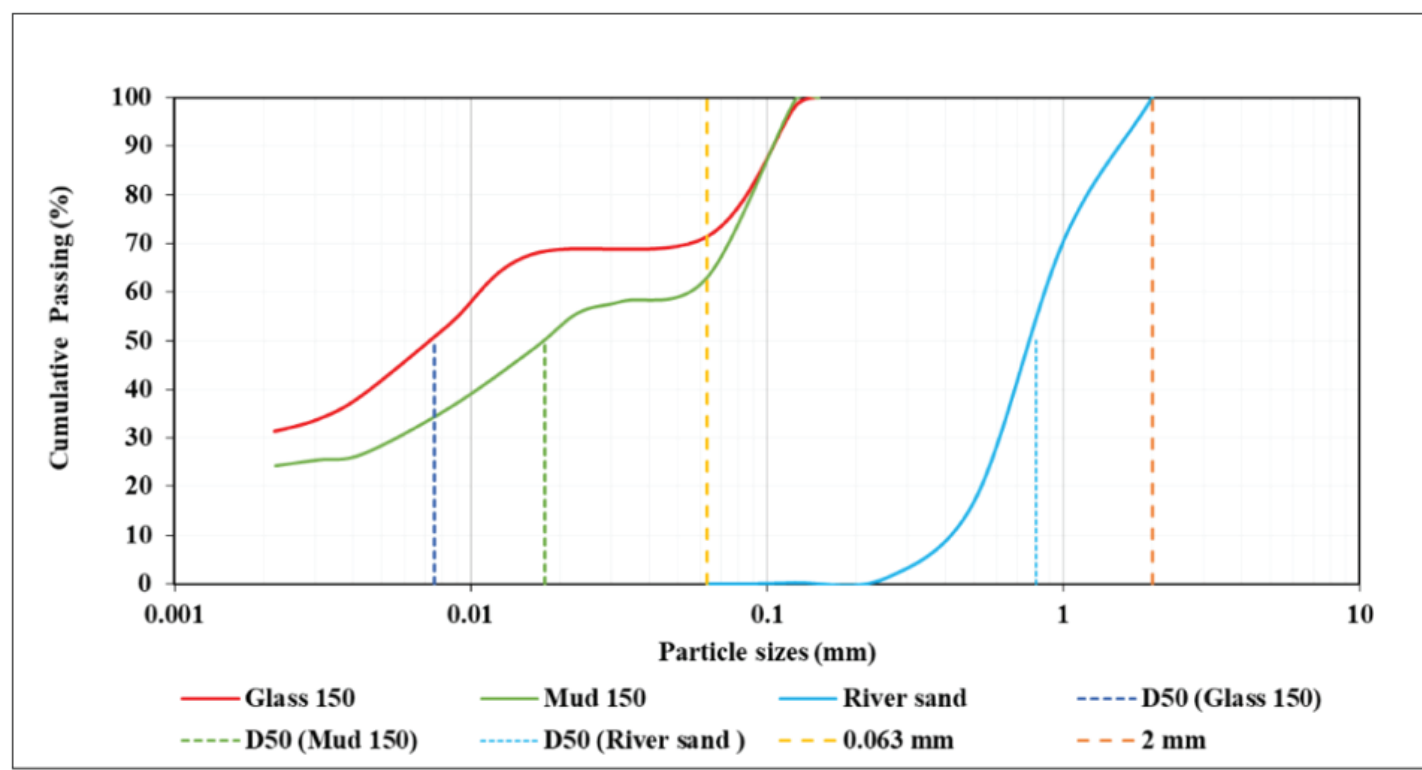

Figure 1: Particle sizes analysis of the TMWM, WG, and river sand

Metakaolin (MK) provided by BASF with Specific a Gravity of $2.50\left(\mathrm{~g} / \mathrm{cm}^{3}\right)$ and $\mathrm{pH}=$ 6 (28\% solids). 
The expanded granulated cork (EGC) used was provided by (SOFALCA Sociedade Central de Produtos de Cortiça, Lda, Abrantes, Portugal). Cork particles ranged from 2 to $4 \mathrm{~mm}$, and density ranges from 70 to $80 \mathrm{~kg} / \mathrm{m}^{3}$. Figure 2 . shows the cell structure of the expanded granulated cork.

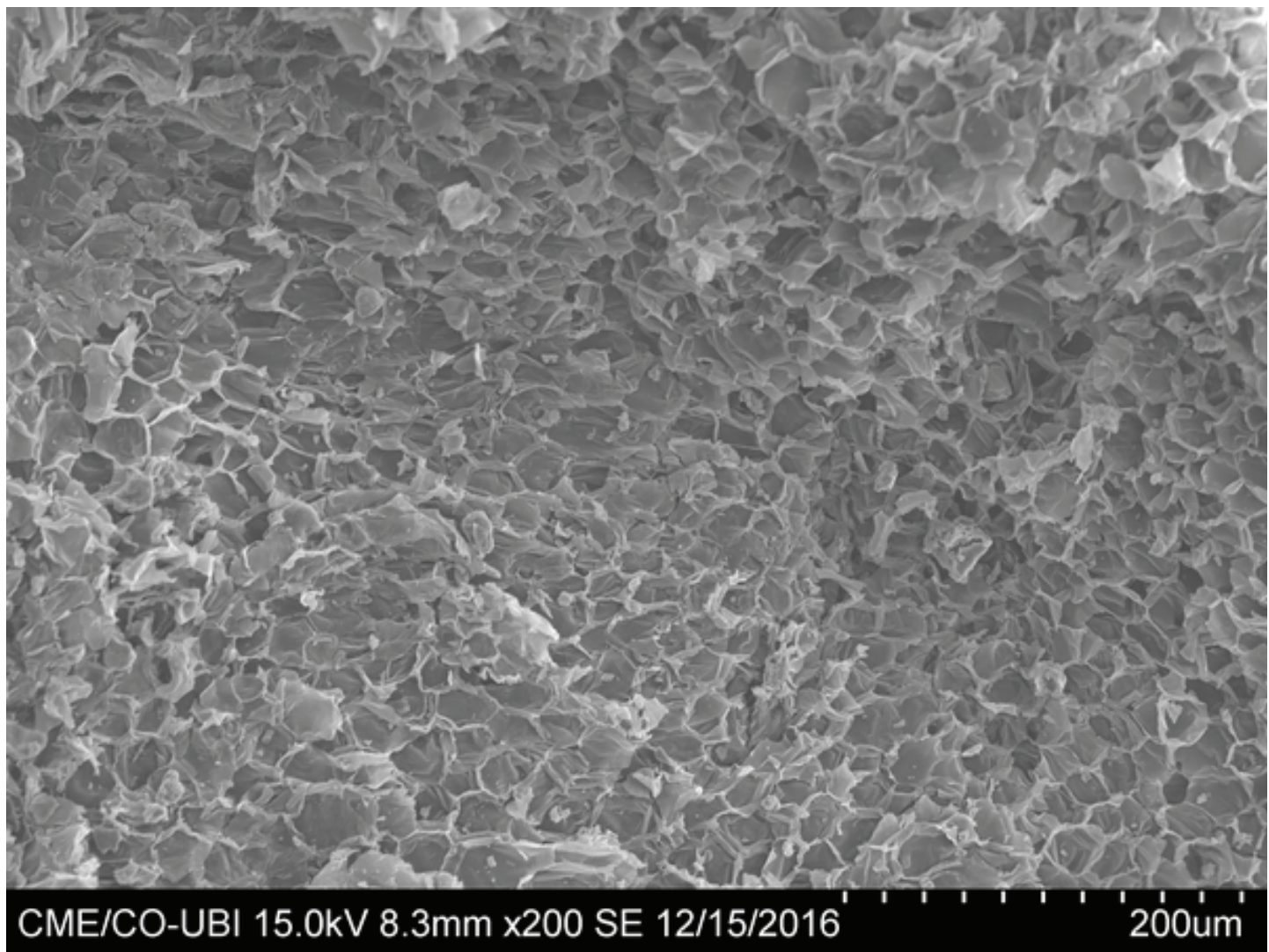

Figure 2: SEM image of the expanded granulated cork (high magnification, UBI optical centre).

In addition, aluminium powder (Al) was used as foaming agent for chemically foaming process, and was provided by ACROS organics with a purity and molar mass of $99 \%$ and $26.98 \mathrm{Al}$, respectively. Aluminium powder was used in this study with a very small content ranging from $0.1 \mathrm{~g}$ to $0.5 \mathrm{~g}$.

The typical chemical compositions of the powders are shown in Table 1. The composition was determined, in several samples of TMWM, WG and MK, through energy dispersive spectrometry (SEM/EDS) at UBI's (University of Beira Interior) optical centre.

A commercial sodium silicate $\mathrm{Na}_{2} \mathrm{SiO}_{3}$ (SS) solution with the composition $\mathrm{SiO}_{2} /$ $\mathrm{Na}_{2} \mathrm{O}=3.2$, and Sodium hydroxide $\mathrm{NaOH}(\mathrm{SH})$ (98.6\% purity) pellets dissolved in distilled water were mixed to constitute the alkali activators, which were prepared at the laboratory of the University of Beira Interior (UBI). The chemical composition of the activators, given by the suppliers (Quimialmel Quimicos e Minerais, Lda. And José Manuel Gomes dos Santos, Lda.) is shown in Table 2. 
TABLE 1: The chemical composition of TMWM, WG, and MK characterized by SEM.

Chemical compound
$\mathrm{SiO}_{2}$
$\mathrm{Al}_{2} \mathrm{O}_{3}$
$\mathrm{Fe}_{2} \mathrm{O}_{3}$
$\mathrm{SO}_{3}$
$\mathrm{~K}_{2} \mathrm{O}$
$\mathrm{Na}_{2} \mathrm{O}$
$\mathrm{CaO}$
$\mathrm{MgO}$

Blaine Fineness $\left(\mathrm{cm}^{2} / \mathrm{g}\right)$

\begin{tabular}{|c|}
\hline TMWM (\%) \\
\hline 46.67 \\
\hline 19.01 \\
\hline 15.47 \\
\hline 7.90 \\
\hline 4.90 \\
\hline 0.85 \\
\hline 0.69 \\
\hline 4.83 \\
\hline 1142 \\
\hline
\end{tabular}

\begin{tabular}{|c|}
\hline WG (\%) \\
\hline 68.13 \\
\hline 2.80 \\
\hline 2.90 \\
\hline 0.23 \\
\hline 0.86 \\
\hline 12.52 \\
\hline 10.52 \\
\hline 2.04 \\
\hline 1896 \\
\hline
\end{tabular}

\begin{tabular}{|c|}
\hline MK (\%) \\
\hline 52.28 \\
\hline 42.99 \\
\hline 1.49 \\
\hline- \\
\hline 0.94 \\
\hline 0.32 \\
\hline- \\
\hline 0.47 \\
\hline 4467
\end{tabular}

Metakaolin - (BASF- the chemical company)

TABLE 2: Chemical composition of the activators.

Oxide/Materials
$\mathrm{Na}_{2} \mathrm{O}$
$\mathrm{SiO}_{2}$
$\mathrm{Al}_{2} \mathrm{O}_{3}$
$\mathrm{H}_{2} \mathrm{O}$

\section{Chemical composition of the activators $(g)$}

Sodium silicate (SS)

19.37

62.60

0.90

142.32
Sodium Hydroxide (SH)

13.02

0.00

0.00

43.27

\subsection{Methods}

\subsubsection{Mixing alkaline solutions}

The synthesis of the alkali-activated foamed mortar and lightweight foamed mortar includes three steps: (a) preparation of the activation solutions, after the magnetic stirring at a rate of 500 r.p.m for about 5 minutes of (10M) sodium hydroxide $\mathrm{NaOH}$ $(\mathrm{SH})$ with liquid sodium silicate $\mathrm{Na}_{2} \mathrm{SiO}_{3}(\mathrm{SS})$, sodium hydroxide is used only 24 hours after preparation; (b) mixing of raw materials (dry powders, expanded cork granules, and $\mathrm{Al}$ powder) the foamed mortar was prepared by dry mixing the alkali-activated paste, tungsten mining waste mud (TMWM), milled waste glass (WG) and, metakaolin (MK). Different measured amounts of Al powder from $0.1 \mathrm{~g}$ to $0.5 \mathrm{~g}$ were added to the precursors then all dry components were mixed well by hand for 1 minute to obtain a homogeneous pore distribution; and (c) moulding and curing the specimens after mixing solid components with the alkaline activating solution, which is alkali metal hydroxide and sodium silicate, for about 2 minutes at a fast speed. Mixes were manufactured with 
precursor/activator of $(2 ; 1$ and $1.5 ; 1)$ for AA-FM, and AALW-FM, respectively. Activators were prepared by mixing sodium silicate with sodium hydroxide with the same ratio of $\mathrm{SS} / \mathrm{SH}=3 ; 1$ (Sodium silicate/Sodium Hydroxide) to study the effects of adding different amount of $\mathrm{Al}$ powder from $0.1 \mathrm{~g}$, to $0.5 \mathrm{~g}$ on the expansion parameters of the AA-FM and AALW-FM. The reaction between the Al powder and the alkaline activator occurs very quickly, as shown in the equation (1);

$$
2 \mathrm{Al}+2 \mathrm{NaOH}+2 \mathrm{H}_{2} \mathrm{O} \rightarrow 2 \mathrm{NaAlO}_{2}+3 \mathrm{H}_{2} .
$$

\subsubsection{Mix design}

A total of ten alkali-activated foamed mortar and lightweight foamed mortar mixes were produced with different amounts of Al powder; ranging from 0.1 to $0.5 \mathrm{~g}$, as presented in Table 3. The mixes were poured into $\left(100 * 100 * 60 \mathrm{~mm}^{3}\right)$ covered acrylic moulds and placed firstly in the oven at $60^{\circ} \mathrm{C}$ for 24 hours for curing to speed up the alkali activation.

TABLE 3: Mixes proportions.

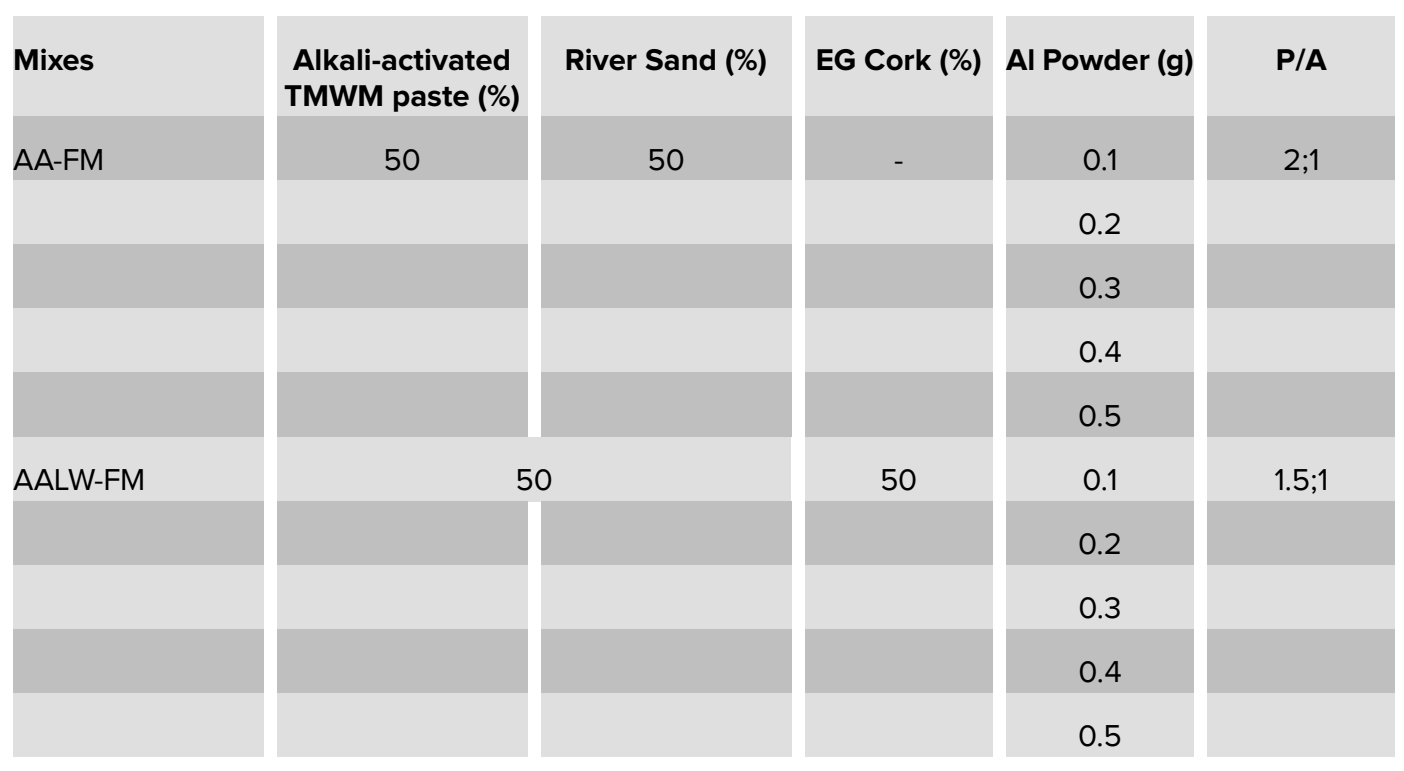

P/A: Precursor/Activator Ratio

After curing in the oven, the samples were removed from the mould and set aside to continue the curing in laboratory conditions, the samples were cut and prepared for the tests in the following days as shown in Table 4. 
TABLE 4: Tests of the alkali-activated foamed mortar and lightweight foamed mortar carried out.

Mixes
AA-FM
AALW-FM

Compressive strength
(MPa)

Density $\left(\mathrm{Kg} / \mathrm{m}^{3}\right)$
$D=m / V$

$\mathrm{Ev}(\%)=(T V-I V) / T V \times 100$

\section{Results and Discussion}

Table 5. shows the compressive strength, density and expansion volume of the AA-FM and AALW-FM.

TABLE 5: Compressive strength, density, and expansion volume results.

\begin{tabular}{|l|l|l|c|c|c|}
\hline $\begin{array}{l}\mathbf{F}_{c 28} \text { AA-FM } \\
(\mathbf{M P a})\end{array}$ & $\begin{array}{c}\mathbf{F}_{c 28} \text { AALW-FM } \\
(\mathbf{M P a})\end{array}$ & $\begin{array}{c}\text { Density } \\
\text { AA-FM } \\
\left(\mathbf{K g} / \mathbf{m}^{3}\right)\end{array}$ & $\begin{array}{c}\text { Density } \\
\text { AALW-FM } \\
\left(\mathbf{K g} / \mathbf{m}^{3} \mathbf{)}\right.\end{array}$ & AA-FM Ev (\%) & $\begin{array}{c}\text { AALW-FM Ev } \\
\text { (\%) }\end{array}$ \\
\hline 13.23 & 4.14 & 1911.62 & 1544.48 & 12.16 & 4.38 \\
\hline 7.06 & 2.72 & 1673.47 & 1392.01 & 23.70 & 19.62 \\
\hline 4.82 & 1.76 & 1462.94 & 1207.07 & 46.47 & 22.94 \\
\hline 3.13 & 1.36 & 1365.59 & 1093.88 & 64.74 & 31.53 \\
\hline 3.24 & 1.31 & 1337.72 & 1077.56 & 81.54 & 40.45 \\
\hline
\end{tabular}

Ev: expansion volume; $-\mathbf{F}_{c 28}$; Compressive strength at 28 days

\subsection{Compressive strength}

The compressive strength test for the AA-FM and AALW-FM was carried on AUTOGRAPH AGS-X, $10 \mathrm{KN}$ SHIMADZU testing equipment. For each mixture, three $(25 \times 25$ $\left.\times 25 \mathrm{~mm}^{3}\right)$, and $\left(40 \times 40 \times 40 \mathrm{~mm}^{3}\right)$ cubes were tested for the AA-FM and AALW-FM respectively. The cubes were obtained by cutting the casted $100 \times 100 \times 60 \mathrm{~mm}^{3}$ with a diamond cutting blade.

The compressive strength results are presented in Figure 3. It is observed that the highest compressive strength values are achieved thru samples with the less amount of Al powder that is with less porosity. Compressive strength results for all samples with diverse amounts of Al powder ranged between 1.31MPa and 13.23 MPa.

Therefore, the increase of Al powder amounts decreases the density and high porosity which results in a gradual decrease of the compressive strength. As it was expected, the compressive strength is strongly affected by the porosity of the alkaliactivated lightweight foamed mortar. 


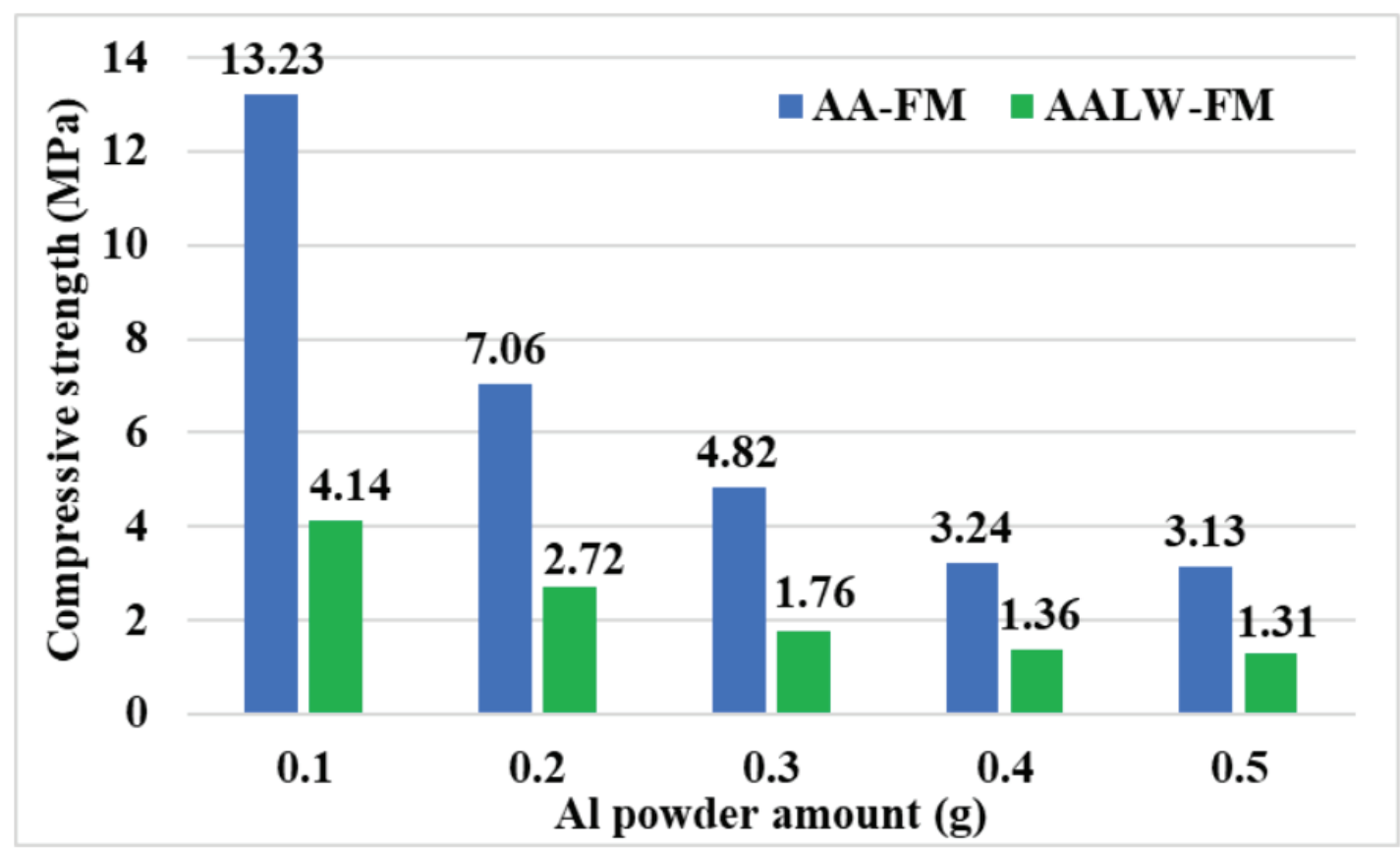

Figure 3: The compressive strength of the AA-FM and the AALW-FM at 28 days.

\subsection{Dry density and porosity}

The density of the AA-FM and AALW-FM were determined by measuring the weight of specimens with a precision balance scale and their dimensions with a precision electronic calliper. The density $(\mathrm{d})$ of the samples was computed by dividing the dry mass $(\mathrm{m})$ by the volume (v) (i.e. so-called geometrical density). Cubic specimens $\left(25^{*} 25^{*} 25 \mathrm{~mm}^{3}\right)$ were used for the AA-FM and $\left(40 * 40 * 40 \mathrm{~mm}^{3}\right)$ used for the AALW-FM, for dry density measurements.

The dry density of the alkali-activated foamed mortar is reported in Figure 4. It is observed that incorporating cork particles (EGC) to the precursors lead to a low density. On the other hand, the increase of the porosity, through chemical foaming by Al powder also decreases density. The lowest density for each type of mortar was achieved at about $1337 \mathrm{Kg} / \mathrm{m}^{3}$ and $1077 \mathrm{Kg} / \mathrm{m}^{3}$ for the AA-FM and the AALW-FM, respectively, when adding a large amount of Al powder $(0.5 \mathrm{~g})$. Furthermore, the increase of the Al powder amount enlarges the pore size of the samples, and several voids inside the material filled with air could be generated, thus resulting in the reduction of density.

\subsection{Expansion volume}

Figures. 5 and 6 show a cross-section of the AA-FM specimens obtained with different amounts of Al powder. The highest expansions volume was obtained by adding $0.5 \mathrm{~g}$ of 


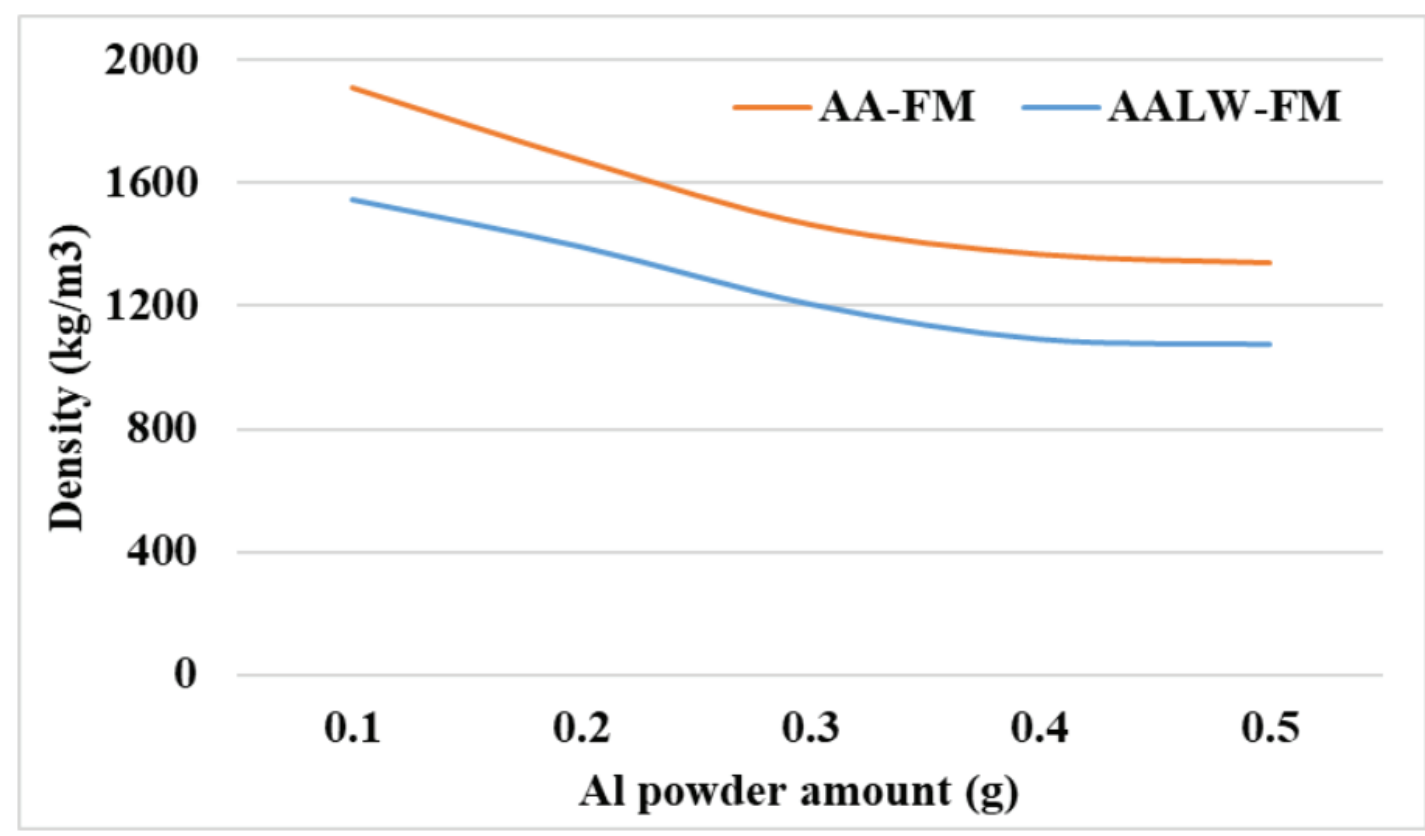

Figure 4: The relation between dry density and the Al powder amounts of the AA-FM and AALW-FM.

Al powder was about $81.54 \%$, and $40.45 \%$ for the AA-FM and the AALW-FM, respectively. The expansion volume was obtained with Eq. (2). The overall results are presented in Table 5.

$$
E v=\frac{T v-I v}{T v} * 100
$$

Ev: Expansion volume (\%).

Tv: Total volume $\left(\mathrm{cm}^{3}\right)$ - (height of sample at the end of the experiment).

Iv: Initial volume $\left(\mathrm{cm}^{3}\right)$ - (height of sample at the start of the experiment).

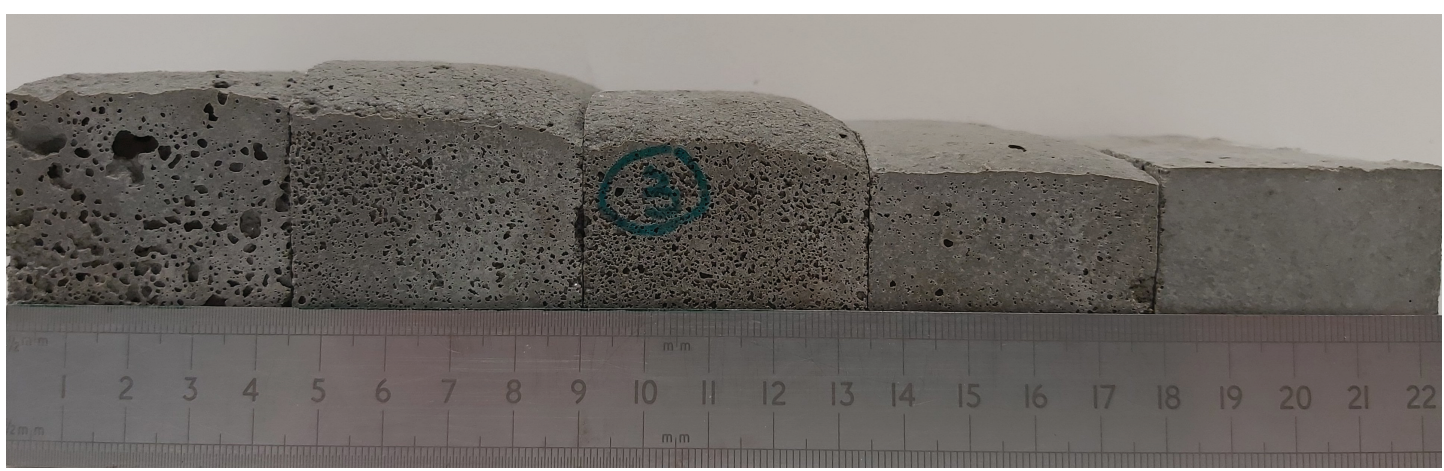

Figure 5: Cross-section image of the AA-FM versus Al powder content.

It is observed that the expansion volume during the foaming process is directly proportional to the increase of the Al powder dosage. The expansion volume is also affected by the expanded granulated cork (EGC) particles which can be noted since the same amount of Al powder does not lead to the same expansion volume for the AA-FM 


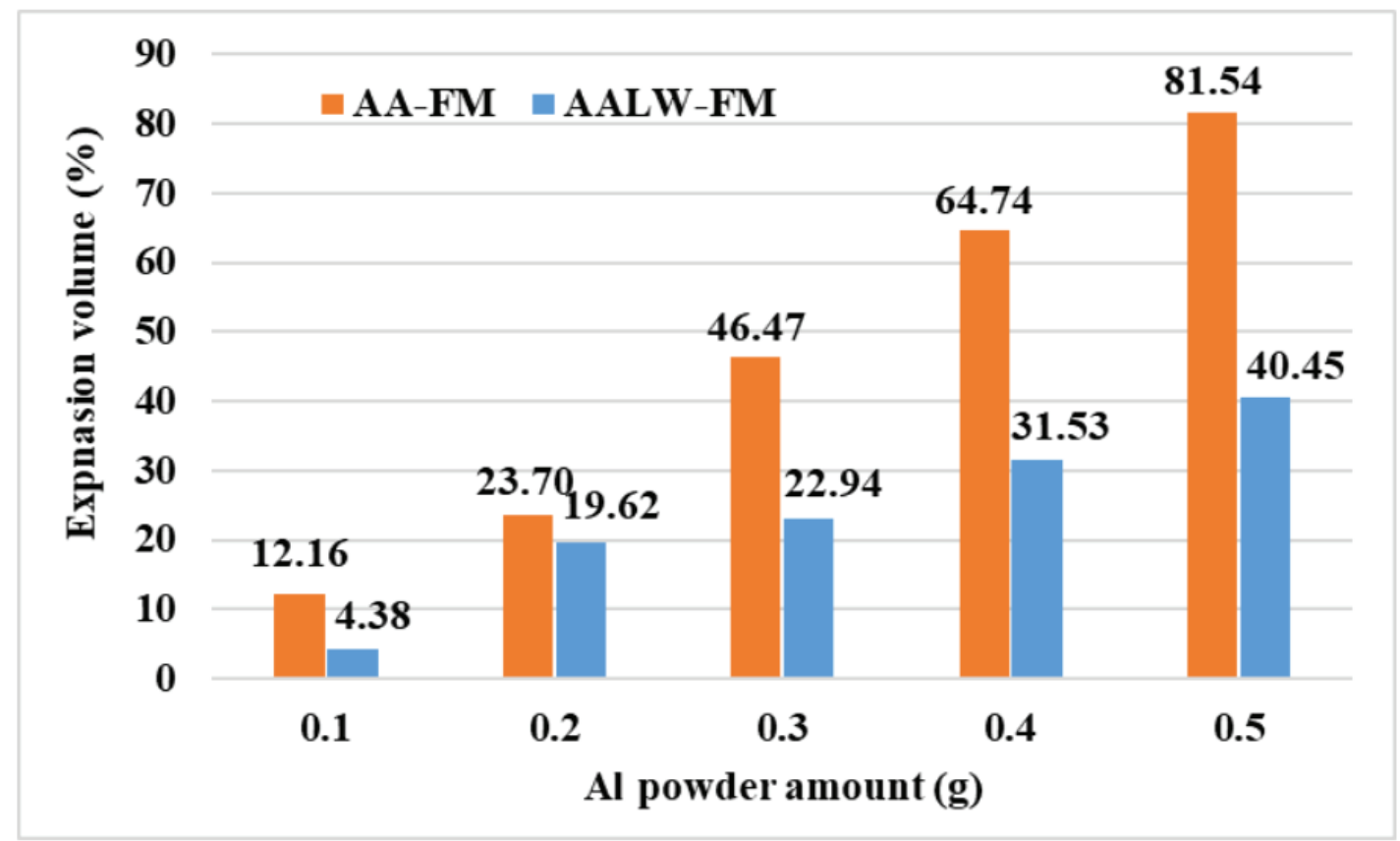

Figure 6: Expansion volume, versus Al powder content of the AA-FM and AALW-FM.

and AALW-FM. Additionally, it was also observed that when increasing the Al powder mass, the expansion time decreases due to the faster reaction between the Al powder and the catalyser $(\mathrm{NaOH})$ present in the alkaline liquid activator.
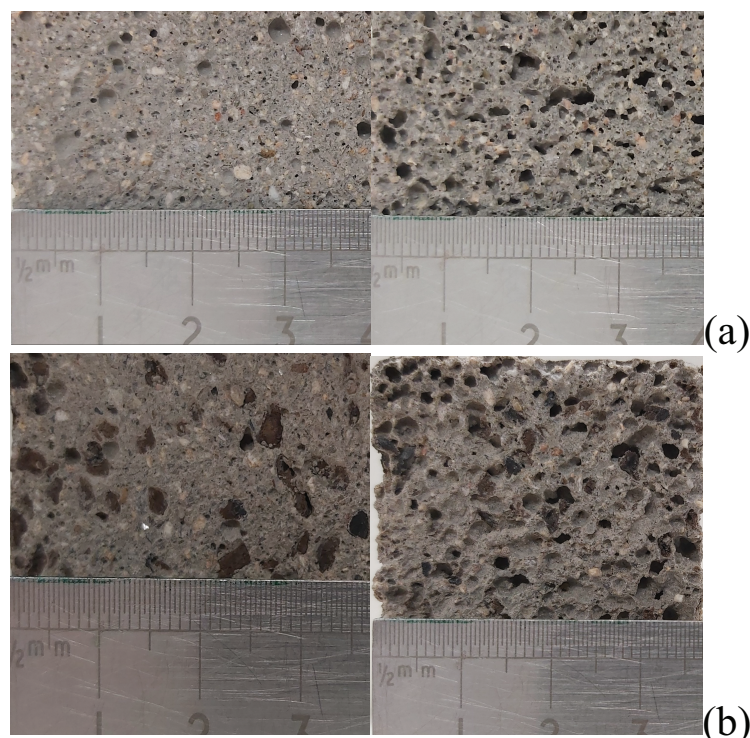

(a)

(b)

Figure 7: Photographs of the central foam section of the samples with small and large amount of Al powder (a) AA-FM, (b) AALW-FM.

It is also observed on Figure. 7 that the formation of large pores appears to be more dependent on the amount of Al. The amount of Al powder affects the morphology of the pores and several small pores formed (up to 1 or $2 \mathrm{~mm}$ diameter) appeared when using 
a little amount of Al powder, while large pores (more than $2 \mathrm{~mm}$ diameter) appeared when using a large amount of Al powder.

\section{Conclusion}

The study was a development of alkali-activated lightweight foamed mortar tungsten mining waste mud-based with aluminium powder using a combination of $50 \%$ alkaliactivated paste (blend of $70 \%$ TMWM, $20 \%$ waste glass (WG), and $10 \%$ metakaolin $(M K))$, and $50 \%$ river sand by incorporating expanded granulated cork (EGC), together with the chemical foaming with aluminium powder (Al). The following findings were made:

- Highly porous foams were obtained through the increase of the Al powder amount thus resulting in the decrease of the density of the AA-FM and the AALW-FM.

- The lowest density was achieved at about $1337 \mathrm{Kg} / \mathrm{m}^{3}$, and $1077 \mathrm{Kg} / \mathrm{m}^{3}$ of the AAFM and the LWAA-FM respectively, when adding $0.5 \mathrm{~g}$ of the Al powder amount.

- The compressive strength results of the produced AA-FM and the AALW-FM are relatively good (13.23MPa, and 4.14MPa were obtained for the highest porosity when using $0.5 \mathrm{~g}$ I powder, respectively).

- The highest expansion volume was obtained for $0.5 \mathrm{~g} \mathrm{Al}$ powder of about 81\%, and $40 \%$ for the AA-FM and the AALW-FM respectively.

- The results showed that cork particles have a potential impact on the density reduction besides, Al powder create a porous system on the AALW-FM.

- Open celled hardened of the AA-FM and AALW-FM with tungsten mining waste mud-based shows promise as thermal insulation material in some situations.

\section{References}

[1] Badanoiu, A.l., et al. T(2015). Preparation and characterization of foamed geopolymers from waste glass and red mud. Constr. Build. Mater., vol. 84, pp. 284293.

[2] UI Haq, E., Kunjalukkal Padmanabhan S., and Licciulli, A. (2015). Microwave synthesis of thermal insulating foams from coal derived bottom ash. Fuel Process. Technol. vol. 130 , pp. $263-267$.

[3] Zhang, Z., et al. (2014). Geopolymer foam concrete: An emerging material for sustainable construction. Constr. Build. Mater., vol. 56, pp. 113-127. 
[4] Beghoura, I., et al. (2017). Feasibility of alkali-activated mining waste foamed materialsincorporating expanded granulated cork. Min. Sci. vol. 24, pp. 7-28.

[5] Kovalchuk, P.V.K.AE.G.Y. (2007). Directed synthesis of alkaline aluminosilicate minerals in a geocement matrix. Journal of Materials Science, vol. 42, pp. 2944 2952.

[6] Krivenko, P. and Kovalchuk, G. (2015). Achieving a heat resistance of cellular concrete based on alkali activated fly ash cements. materials and Structures, vol. 48, pp. 599606.

[7] Arellano Aguilar, R., Burciaga Díaz, O. and Escalante García, J.I. (2010). Lightweight concretes of activated metakaolin-fly ash binders, with blast furnace slag aggregates. Constr. Build. Mater. vol. 24, pp.1166-1175.

[8] Narayanan, N. and Ramamurthy K. (2000). Structure and properties of aerated concrete: a review. Cement \& Concrete Composites, vol. 22, pp. 321-329.

[9] Kearsley, E.P. and Wainwright, P.J. (2001). The effect of high fly ash content on the compressive strength of foamed concrete, Cement and Concrete Research, 31 (2001) 105-112.

[10] Davidovits, J. (2011). Geopolymer chemistry \& applications 3rd edition, Institut Géopolymère, Geopolymer Institute, Saint-Quentin, France.

[11] Masi, G. et al. (2014). A comparison between different foaming methods for the synthesis of light weight geopolymers. Ceram. Int. vol. 40, pp.13891-13902.

[12] Sanjayan, J.G., et al. (2015). Physical and mechanical properties of lightweight aerated geopolymer. Constr. Build. Mater., vol.79, pp. 236-244.

[13] Matos, A.M., Nunes, S. and Sousa-coutinho, J. (2015). Cork waste in cement based materials. JMADE, vol. 85, pp. 230-239.

[14] Beghoura, I. et al. (2019). Expansion volume of alkali activated foamed cork composites from tungsten mining mud waste with aluminium. MATEC Web of Conferences. 274. 03002. 10.1051/matecconf/201927403002.

[15] Akthar, F.K. and Evans, J.R.G. (2010). High porosity (> 90\%) cementitious foams. Cem. Concr. Res., vol. 40, pp. 352-358.

[16] Kreft, O. (2011). Pore size distribution effects on the thermal conductivity of light weight autolaved aerated concrete. 5th Int. Conf. Autoclaved Aerated Concr. Bydgoscsz, 2011.

[17] Beghoura, I. and Castro-Gomes, J. (2019). Design of alkali-activated aluminium powder foamed materials for precursors with different particle sizes. Constr. Build. Mater., vol. 224, pp. 682-690. 
[18] Panesar, D.K. and Shindman, B. (2012). The mechanical, transport and thermal properties of mortar and concrete containing waste cork. Cem. Concr. Compos., vol. 34 pp. 982-992.

[19] Karade, S.R., Irle M., and Maher, K. (2006). Influence of granule properties and concentration on cork-cement compatibility. Holz als Roh- und Werkstoff, vol. 64, pp. 281-286.

[20] Vaou, V. and Panias, D. (2010). Thermal insulating foamy geopolymers from perlite. Miner. Eng., vol. 23, pp. 1146-1151.

[21] Buchwald, A., Kaps, C. and Hohmann, M. (2003). Alkali-activated binder and pozzolan cement binders-compete reaction or two side of the story? 11 Th Int. Congr. Chem. Cem. Pp. 1238-1246.

[22] Castro-Gomes, J. (2017). Alkali-activation of tungsten mining waste mud blended with waste glass: reactivity, performance and innovative applications. http://hdl.handle. net/10400.6/6858. 